\title{
COMMENTARY
}

\section{TIMP-1 gene polymorphism: are genetics able to predict outcome of septic patients?}

\author{
Michael Behnes ${ }^{1}$, Thomas Bertsch² and Ursula Hoffmann*1 \\ See related research by Lorente et al., http://ccforum.com/content/17/3/R94
}

\begin{abstract}
The multicenter study conducted by Lorente and coworkers - published in the previous issue of Critical Care - suggests that levels of tissue inhibitor of metalloproteinase (TIMP)-1 in association with the 372 T/C genetic polymorphism of TIMP-1 are promising markers to predict the clinical outcome of septic patients. TIMPs bind to active matrix metalloproteinases and, amongst other effects, inhibit their proteolytic activity of the extracellular matrix. Previous clinical studies showed increased plasma levels of TIMP-1 in nonsurvivors of sepsis, and showed associations between the 372 T/C genetic polymorphism of TIMP-1 and increased risk of developing certain diseases. In recent years, there has been great interest in understanding whether genetic determinants of the host response to systemic infections are associated with poor outcome. Furthermore, the pharmacogenomics of sepsis may allow us to target immune-modulating therapies. Measurement of TIMP-1 protein levels and TIMP-1 polymorphism $372 \mathrm{~T} / \mathrm{C}$ in the intensive care setting could therefore be an attractive noninvasive tool to determine the outcome of septic patients, and might help to select patients potentially benefitting from a target-specific immune-modulatory therapy directed to matrix metalloproteinase/TIMP homeostasis.
\end{abstract}

\section{Introduction}

In the previous issue of Critical Care, the Spanish group of Lorente and colleagues reports results in which the role of the $372 \mathrm{~T} / \mathrm{C}$ polymorphism of tissue inhibitor of metalloproteinase (TIMP)-1 (rs 4898) and serum levels of TIMP-1 were related to the outcome of 275 patients with

*Correspondence: ursula.hoffmann@umm.de

11st Department of Medicine, Faculty of Clinical Medicine Mannheim, University of Heidelberg, Theodor-Kutzer-Ufer 1-3, D-68167 Mannheim, Germany

Full list of author information is available at the end of the article severe sepsis [1]. They found the T-allele in the $372 \mathrm{~T} / \mathrm{C}$ genetic polymorphism of TIMP-1 and increased levels of TIMP-1 to be associated with lower survival rates, and suggest that this genetic polymorphism may have prognostic implications in severe septic patients.

Sepsis represents a systemic inflammatory response to an infectious agent and may lead to multiple organ failure, increased mortality and costs. Genetic testing has been discussed as a strategy to identify septic patients with a poor prognosis. Advances in genetic sequence analysis and high-throughput platform analysis of gene expression improved the understanding of immunopathogenetics during sepsis [2].

TIMPs naturally occur as inhibitors of matrix metalloproteinases (MMPs), whilst additionally revealing growth factor functions [3]. TIMP-1 itself inhibits almost all of the different MMP subtypes [3]. TIMP-1 activates human granulocytes, protecting them from apoptosis and blocking their transmigration during inflammation [4]. Several studies showed increased protein levels of MMPs and TIMPs, and evaluated the prognostic value of TIMP-1 in patients with severe sepsis $[5,6]$.

Increasing evidence suggests that differences of a specific disease manifestation and outcome may result from the patient's individual genetic disposition. A study by Skarmoutsou and colleagues demonstrated the prognostic impact of the 372 T/C TIMP-1 genetic polymorphism for the onset of systemic sclerosis in women [7]. An association of genetic polymorphisms of the X-linked TIMP-1 gene with the risk of developing certain other diseases has been reported, the 372 T/C TIMP-1 polymorphism being the most studied variant [7-9].

\section{TIMP-1 as a biomarker in the ICU}

The association between levels of TIMP-1 and the 372 T/C TIMP-1 polymorphism was previously evaluated in patients with acute heart failure, left ventricular dysfunction and ST-elevation myocardial infarction treated by primary percutaneous coronary intervention [10]. In this previous study, an independent relationship between an exon 5 TIMP-1 gene polymorphism, TIMP-1 levels and left ventricular dysfunction was not shown. 
The majority of sepsis studies evaluated other inflammatory mediators, such as TNF and its polymorphisms being associated with increasing stages of sepsis $[11,12]$. A meta-analysis of two common Toll-like receptor 4 polymorphisms showed no strong correlation with the development of sepsis [13]. Lorente and coworkers demonstrated for the first time the association of SNP 372 T/C of TIMP-1 and TIMP-1 levels with survival in septic patients [1].

While the $372 \mathrm{~T} / \mathrm{C}$ genetic polymorphism of TIMP-1 is located on the $\mathrm{X}$ chromosome, the study by Lorente and colleagues showed no differences in survival between women with $\mathrm{C} / \mathrm{C}, \mathrm{C} / \mathrm{T}$ and $\mathrm{T} / \mathrm{T}$ alleles, but the $\mathrm{T}$-allele was associated with higher mortality in men [1]. Nonsurvivors of sepsis showed higher TIMP-1 protein levels than survivors, but levels of TIMP-1 were notably lower as described in other series $[5,14]$. Septic animal models showed that modulators of MMP/TIMP activity reduce TIMP-1 and improve the prognosis [15].

Emergent is the question of whether determination of the $372 \mathrm{~T} / \mathrm{C}$ polymorphism of TIMP-1 could help the intensive care physician in the selection of patients who may benefit from therapeutic modulation of MMP/TIMP activity. However, as there is extensive diversity in inflammatory pathways and immune response during sepsis, the functional and clinical significance of one SNP may not be the only marker for prognosis assessment in the large puzzle of sepsis.

\section{Limitations of this study}

A limitation of the study by Lorente and colleagues is the small sample size, making prognostic implications by one SNP challenging. A second limitation is the fact that the study group only tested the rs 4898 SNP of TIMP-1, a tag SNP for the region of interest. Whether this SNP is linked to other SNPs associated with the same effect could be of interest. The susceptibility to sepsis is probably affected by multiple genes rather than one single mutation. Furthermore, measurement of one SNP as a tool for identifying septic patients at high risk of mortality is time consuming and costly, and thus may not be practical in the clinical routine. Finally, an important limitation of any association in this study is that it cannot establish a cause-effect relationship, but may only represent an epiphenomenon.

\section{Conclusion}

Genetic approaches to patients with severe sepsis have grown over the last decade. Until now, none of these results have been translated directly to clinical therapy. The determination of the $372 \mathrm{~T} / \mathrm{C}$ polymorphism of TIMP-1 - as a new genetic biomarker for the severity of sepsis and for mortality assessment in critically ill patients - may provide a future tool. Whether biomarker determination such as TIMP-1 levels and genotyping could optimize treatment and sepsis outcome requires further methodological comparable research to bridge the gap between laboratory and bedside. There is still a long road ahead of us until the ideal marker is found and is readily available in clinical practice.

\section{Acknowledgements}

The present work was supported by the Deutsches Zentrum für HerzKreislauf-Forschung (German Centre for Cardiovascular Research) and by the BMBF (German Ministry of Education and Research).

\section{Abbreviations}

MMP, matrix metalloproteinase; SNP, single nucleotide polymorphism; TIMP, tissue inhibitor of metalloproteinase; TNF, tumor necrosis factor.

\section{Competing interests}

The authors declare that they have no competing interests.

\section{Author details}

'First Department of Medicine, Faculty of Medicine Mannheim, University of Heidelberg, Theodor-Kutzer-Ufer 1-3, D-68167 Mannheim, Germany. ${ }^{2}$ Institute of Clinical Chemistry, Laboratory of Medicine and Transfusion Medicine Central Laboratory, Clinic Nuremberg, Prof.-Ernst-Nathan-Straße 1, D-90419 Nuremberg, Germany.

Published: 17 July 2013

\section{References}

1. Lorente L, Martín MM, Plasencia F, Solé-Violán J, Blanquer J, Labarta L, Díaz C, Borreguero-León JM, Jiménez A, Páramo JA, Orbe J, Rodríguez JA, Salido E: The 372 T/C genetic polymorphism of TIMP-1 is associated with serum levels of TIMP-1 and survival in patients with severe sepsis. Crit Care 2013, 17:R94.

2. Tang BM, Huang SJ, MCLean AS: Genome-wide transcription profiling of human sepsis: a systematic review. Crit Care 2010, 14:R237.

3. Iyer RP, Patterson NL, Fields GB, Lindsey ML: The history of matrix metalloproteinases: milestones, myths, and misperceptions. Am J Physiol Heart Circ Physiol 2012, 303:H919-H930.

4. Chromek M, Tullus K, Lundahl J, Brauner A: Tissue inhibitor of metalloproteinase 1 activates normal human granulocytes, protects them from apoptosis, and blocks their transmigration during inflammation. Infect Immun 2004, 72:82-88.

5. Hoffmann U, Bertsch T, Dvortsak E, Liebetrau C, Lang S, Liebe V, Huhle G, Borggrefe M, Brueckmann M: Matrix-metalloproteinases and their inhibitors are elevated in severe sepsis: prognostic value of TIMP-1 in severe sepsis. Scand J Infect Dis 2006, 38:867-872.

6. Lorente L, Martín MM, Labarta L, Díaz C, Solé-Violán J, Blanquer J, Orbe J, Rodríguez JA, Jiménez A, Borreguero-León JM, Belmonte F, Medina JC, Llimiñana MC, Ferrer-Agüero JM, Ferreres J, Mora ML, Lubillo S, Sánchez M, Barrios Y, Sierra A, Páramo JA: Matrix metalloproteinase-9, -10, and tissue inhibitor of matrix metalloproteinases- 1 blood levels as biomarkers of severity and mortality in sepsis. Crit Care 2009, 13:R158.

7. Skarmoutsou E, D'Amico F, Marchini M, Malaponte G, Scorza R, Mazzarino MC: Association of TIMP-1 +372 SNP with digital ulcer manifestation in female systemic sclerosis patients. Human Immunol 2012, 73:950-953.

8. Hung KH, Hung HW, Yang HB, Lu CC, Wu JJ, Sheu BS: Host single nucleotide polymorphisms of MMP-9 -1562/TIMP-1 372 have gender differences in the risk of gastric intestinal metaplasia after Helicobacter pylori infection. Helicobacter 2009, 14:580-587.

9. Yi YC, Chen MK, Chen LY, Ho ES, Ying TH, Wang PH, Yang SF: Genetic polymorphism of the tissue inhibitor of metalloproteinase- 1 is associated with an increased risk of endometrial cancer. Clin Chim Acta 2009, 409:127-131.

10. Goldbergova MP, Parenica J, Jarkovsky J, Kala P, Poloczek M, Manousek J, Kluz K, Kubkova L, Littnerova S, Tesak M, Toman O, Pavek N, Cermakova Z, Tomandl J, Vasku A, Spinar J: The association between levels of tissue inhibitor of metalloproteinase- 1 with acute heart failure and left ventricular dysfunction in patients with ST elevation myocardial infarction treated by primary percutaneous coronary intervention. Genetic Test Mol Biomarkers 2012, 16:1172-1178. 
11. Kothari N, Bogra J, Abbas H, Kohli M, Malik A, Kothari D, Srivastava S, Singh PK: Tumor necrosis factor gene polymorphism results in high TNF level in sepsis and septic shock. Cytokine 2013, 61:676-681.

12. Peres Wingeyer SD, Cunto ER, Nogueras CM, San Juan JA, Gomez N, de Larranaga GF: Biomarkers in sepsis at time zero: intensive care unit scores, plasma measurements and polymorphisms in Argentina. J Infect Dev Ctries 2012, 6:555-562.

13. Zhu L, Li X, Miao C: Lack of association between TLR4 Asp299Gly and Thr399lle polymorphisms and sepsis susceptibility: a meta-analysis. Gene 2012, 501:213-218

14. Lauhio A, Hastbacka J, Pettila V, Tervahartiala T, Karlsson S, Varpula T, Varpula M, Ruokonen E, Sorsa T, Kolho E: Serum MMP-8, -9 and TIMP-1 in sepsis: high serum levels of MMP-8 and TIMP-1 are associated with fatal outcome in a multicentre, prospective cohort study. Hypothetical impact of tetracyclines. Pharmacol Res 2011, 64:590-594.

15. Zhu S, Ashok M, Li J, Li W, Yang H, Wang P, Tracey KJ, Sama AE, Wang H: Spermine protects mice against lethal sepsis partly by attenuating surrogate inflammatory markers. Mol Med 2009, 15:275-282.

doi:10.1186/cc12799

Cite this article as: Behnes M, et al: TIMP-1 gene polymorphism: are genetics able to predict outcome of septic patients? Critical Care 2013, 17:170 